\title{
The Scientific Construction of a Law Way to Practice Socialist Core Values in Colleges and Universities from the Perspective of the Internet Plus
}

\author{
Yu Chen ${ }^{1, a}$, Jiajia Wang ${ }^{2, b}$ \\ 1 Taizhou Polytechnic College, Jiangsu Taizhou, China, 225300 \\ a38907447@qq.com, bwangjiajia_99@163.com
}

Keywords: Internet plus, moral and law, personnel training, core value, law way

\begin{abstract}
Law and morality is not only the essential feature of the rule of law talents training in colleges and universities, but also all types of personnel training needs of the times, especially in the Internet plus comprehensive law era, to overall strengthen the training of all kinds of "moral and law" talents, indeed, it is indispensable. But in the current, the scientific construct of the effective path guided by the rule of law, earnestly cultivate and practice the socialist core values, is undoubtedly the most important, the most efficient, and the most realistic choice.
\end{abstract}

\section{Introduction}

On the eve of Youth Day this year, when inspecting China University of Political Science and Law, General secretary Xi Jinping stressed: "The rule of law and rule of virtue should be grasped both links at the same time and attached sufficient importance to both," and "nurture men of talent, minors in moral and law, training a large number of high-quality talents of law". ${ }^{[1]}$ This is an important indicator to strengthen and improve the cultivation of talents, the ideological and political work and the rule of law publicity and education in colleges and universities under the new situation, open a new perspective for the further promote the cultivation and practice the deepening of the socialist core values in Colleges and Universities, provided a new way of thinking, pointed out a new direction, opened up a new path.

\section{Law and morality is the most distinctive characteristic of the work of personnel training in Colleges and Universities}

The essence of education is "moral education", general secretary Xi Jinping has repeatedly stressed the importance of morality education. This time, he put forward new requirements for "moral and law " to cultivate high-quality rule of law talents, to further enrich the connotation of rule of law talents, identify a new target for personnel training in colleges and universities. If you just literally, this is the specific requirements for the rule of law in higher education. But from the this grander vision, theory and practice of the Party governing the country, this is not only the essence of the rule of law personnel training requirements, but also the fundamental mission of all personnel training. From the law of growth, morality is the fundamental philosophy of life, and is the guarantee of success. From the development state of the law, the book Zuo Zhuan had said that morality is the foundation of a country. Although the rule of law is the basic way of national governance, it always cannot do without strong support of virtue. At any time, legal and reasonable are different, but the law must be based on the most basic social morality as the foundation, lost the moral foundation, the rule of law is the inevitable savage imperious, has to be interpreted as brutal tyranny rule, would not be long.

Whether the rule of law or morality, all need the moral nourishment, all need moral citizens as solid support. If the moral consciousness and moral practice ability is not promote, it is impossible to form good social morality, occupation morality, family virtue and individual moral. Not only the rule of law will lose fertile soil of morality, virtue itself is just like a tree without roots, water without a source. Therefore, to achieve the moral and legal treatment together, it is not only needs a large 
number of high-quality the rule of law talents minors in morality and law-- the rule of law of direct and urgent realistic need, but also need more qualified citizens minors in morality and law-- the fundamental premise and the important basis of rule of virtue and rule of law. As the first position to train legal personnel and qualified citizens, colleges and universities must always adhere to the "simultaneous development of morality and law" and comprehensively improve the training quality of all personnel, including the rule of law talents, we should vigorously improve the legal professional level and moral standard, also effectively improve the legal quality and moral standards of other talents, this is the most distinctive characteristic of talents cultivation of colleges and universities, also the top priority of Ideological and political work in colleges and universities under the new situation.

\section{The path of law is the inevitable choice to cultivate and practice the core values of colleges and universities}

Whether it is the rule of law talents, or qualified citizens, moral standards are the same, the level of the rule of law is just a professional and non professional distinction, the rule of law inherent quality, cultivation standard is the same, it must be "simultaneous development of morality and law". To do this, colleges and universities have a lot of work to do, and a lot of tasks to be completed, but the most important, the most efficient, is earnestly to cultivate and practice the core values. This is the primary task of cultivating all kinds of "moral and law" talents, and is the first choice to consolidate the moral foundation of "the moral and legal treatment together". The socialist core values is the country's greatness, the fundamental moral, and has a strong pursuit of legal value, profoundly answer the major issues to construct what kind of country and society, cultivate what kind of citizen. ${ }^{[2]}$ In the fourth Plenary Session of the 18th CPC Central Committee the Party put forward clearly, adhere to the combination of the rule of law and virtue, we must vigorously promote the socialist core values, nourish the spirit of rule of law with morality, and put it as one of the five principles of the rule of law to achieve a comprehensive overall goal. At the end of last year, the Central put further requirements of the socialist core values integrate into the construction of the rule of law.

At the same time, the rule of law is the most important factor of value. From the internal structure, the core value pursuit of the rule of law has a unique position and role, not only integrate into the other values, but also has the relative independence, is the greatest common divisor of other core value elements, play a connecting link between the preceding and the following, merge the functions of cohesion, as a hidden main thread, secretly run through other elements, always. First of all, only literally, law is one of the four categories of value orientation of the social level, it is a powerful guarantee to achieve the other three core value elements of the same level, to achieve freedom, equality and justice, the rule of law is not impossible. At the same time, from the analysis of its internal logic, equality is the basic property of the socialist law, adhere to everybody is equal before the law is one of the five principles of the overall goal of comprehensively promote the rule of law, justice is the soul and life of justice which is an important part of the rule of law, is the essential feature and core value pursuing of judicial work, all has the significant feature of rule of law. Secondly, look deeply, the four categories of social harmony value orientation with the rule of law as the core and the soul, complement each other, up to form strong support and protection the value goal on the national level, down to maintain orderly guide and regulate values of citizens level. Thirdly, to a deeper level, whether the level of national value target, or the level of civic value criterion, both implies the inherent requirement of the rule of law: prosperous, democratic, civilized, harmonious four categories, all cannot do without the strong support and effective protection of the rule of law. The democracy and the rule of law is tantamount to one, indivisible, on democracy, we must talk about the rule of law, if democracy don't take the rule of law as the basic form, to be implemented by the system of rules and procedures, can only be a good vision, or is not democratic in the name of democracy implementation. The rule of law is the foundation and the core of the modern system of civilization, is the core of social civilization symbol, is the only way for a civilized nation. Patriotism, dedication, integrity, kindness four categories, also need clear guidance and firm guardian the from 
the rule of law. Good faith is an important ethical basis and the nature of the requirements of the rule of law, the principle of honesty and credit has become a basic principle of law, it is the rule of law which is not marked "rule of law" but with strong attributes to it.

So, from the internal logic relations, not only the value orientation of society has a distinctive point to the rule of law, the other two level also has a strong demands to rule of law. Choose the law way to promote the construction of the core values, make the pursuit of rule of law realized to the vivid concrete practice from the ideological and spiritual level, it can not only best fit the inherent requirements of the socialist core values, but also strong lead, regulate and safeguard the cultivation and practice the core values of other elements. From the "simultaneous development of morality and law " talent training practice needs, using a law way to cultivate and practice the core values, which can effectively strengthen the national virtue, social morals, personal virtue, these fundamental morals affect to the teachers and students, improve their ideological and moral qualities, but also directly regulate to the teachers and students, improve their quality of the rule of law, that is achieve many things at one stroke, twice the result with half the effort.

\section{The scientific construction of the effective path of the rule of law to guide the construction of core values}

Choose the path of law as the basic path, its fundamental purpose is to put construction of the university core values into the orbit of managing the university by law, by the authoritative guide, mandatory norms, solid guarantee and strongly promote of the rule of law, thorough, continuous and stable to promote the whole staff value cognition, value identity and consciously practice of core value. Especially in today's Internet plus era, the network changes or even subverts the interactive mode of people, all kinds of new media platforms fastly emerging like bamboo shoots after a spring rain, exhibits a wide range of infinity and great inclusive, breaking the boundaries of time and space, occupy people's time, once the remotest corner of the earth, now at hand. Network life, the basic way of life, has an extensive, profound, far-reaching influence on all Internet users' ideals and beliefs, the way of thinking, behavior patterns, mental health, including the whole universities staff especially young college students. When the Internet brought great convenience to people, Internet also produced a series of negative effects, not only have a negative impact on thought, moral, psychological, character for students and staff the even politically mislead a few teachers and students.

So, in such a new era of human society, how to use the socialist core values - that is fully reflect the requirements of socialism ideology essence value requirements, to lead the staff and students in the network society. It is not only a basic idea, value goal and value criterion of their firm belief, but also truly as a concrete action, effective realize of the unity of knowledge and action, and gradually form a stable and lasting power of good deeds, it is very urgent and very important. College students today, most of the "95" youth, they have a wide range of knowledge, information sources, active thinking, but the anti-interference ability is not strong, and they are easily disturbed and tempted by various aspects. Every day they cannot do without the network, mobile phone. Network platform, especially WeChat, micro-blog and other new media and mobile clients has become their basic living habits, lifestyle, and even spiritual home. Because there is no fixed value, they are just ordinary "people eat melon", whether in political views, political position, public opinion field, or in some of the focus, common event, onlookers, eat noodles, drink water, if the boot is not timely, guide is not good, some may be opposite.

In this broader perspective, the universities can not only look at the reality of the physical space, but also lock the virtual space of network, and effectively selective focus, apply power at the same time, give prominence to the key points, accurate exertion, comprehensive win network Shangganling battle without smoke, to guide the whole students and staff in the light of its general trend, especially young students to enhance the ability to distinguish right from wrong and beauty from ugliness, so that they can become adults talent better. This requires the effective use of rule of law and the role of the system, lead and protect the construction achievements of all online and offline 
core values with perfect system and rule of law, effectively realize the value cognition, value identity and consciously practice that is usually called "into the brain, into the heart, sincerely carry out". Therefore, the law way in colleges and universities to cultivate and practice the socialist core values, also must be closely linked to the "cognition, identity, practice", "sincerely carry out" with scientific construction.

\subsection{Strengthen the publicity and education of the rule of law and raise the cognitive level of the} whole staff. Know law to believe law. Strengthen the conception of rule of law and the consciousness of rule of law, is a solid foundation to comprehensively promote the rule of law, to cultivate and practice the core values, and strengthen the legal publicity and education is the basis of this foundation. The first function of publicity and education is to improve the cognitive level, thus internalized into the code of conduct, influence and guidance the specific actions of the people. The process of the rule of law publicity and education, which is process of making the spirit of the rule of law, legal knowledge, the value concept and moral orientation advocated by the rule of law known and popular, only the requirements of the rule of law is well known, we could effectively avoid the embarrassment of "excute without teaching". The university must always adhere to the basic principles "comprehensive is the first, deep-going is the main point, innovation must be throughout, solid work is the guarantee", strengthen the rule of law publicity and education. Comprehensive is to ensure full coverage, ensure coverage of three groups: leading cadres at all levels, the key minority; young students, the vast majority; the staff , the main force. Deep-going is the appropriate measures, rich carrier, diverse means, fully mobilize all forces, effectively integrate all kinds of resources, upon layer advance, step by step further, careful, cohesive whole. Innovation is the bold innovation, good at innovation, create ideas, content and form with actual timely, so that it is more popular for the audience. Solid work is to implement, to achieve practical results, upward in line with the central and national policies, down with the actual specific situation, not only follow on line, but also aim at offline, it has strong pertinence, significant effect, unique highlight and brand.

4.2 Strengthen the construction of legal culture and consolidate identity foundation. Trust law to abide by law. Know the law is the basic premise, to really play the role of the rule of law, we must make people sincerely, heartfelt belief in the rule of law, then belief in the value orientation and moral habits of the rule of law. To accomplish this, there are three basic ways. First is the legal publicity and education what I just said, through education to make people know the law, understand the law, so as to establish a strong identity for the rule of law. Second is the rigid constraints of rule of law, by means of punishment make people respect the law, abide by the law, understand the sacrosanct of the rule of law. Third is the culture construction of the rule of law, by means of edify make people reverence for the law, respect for the law, rule of law will be engraved in the depths of the soul. Therefore, the university must take comprehensively promote the law school as a kind of value pursuit and conscious action, make full use of the theory of rule of law research, legal knowledge contest, the rule of law culture square construction, exhibition hall construction, network platform construction of the rule of law, the rule of literary creation, performances and voluntary service of the rule and other various forms, carefully cultivate the campus spirit culture, material culture and behavior culture of the rule of law, and the core value elements of the socialist core values could be part of it naturally. Not only to fully reflect the law of "heteronomy" requirements, but also to effectively reveal the moral "self-discipline" power, to achieve harmony, force collaboratively, complement each other, effect with join forces, enable teachers and students to firmly establish a consciousness, sense and thinking of rule of law imperceptibly, and consciously and unconsciously practice the socialist core values.

\subsection{Strengthen the rule of rigid constraints and enhance the awareness of sincere behavior.} Eliminate the evil, so we could cultivate justice. Practice the core values firmly and unshakable, unswervingly loyal, it is far from enough to just only education and nurture. The rule of law must fully play the rule of praise, disciplinary action, with rigid constraints to promote the true, the good and the beautiful, against the false, the ugly and the evil, make people want more good and avoid evil, sincerely carry out always. On the one hand, good law is the premise of good governance, the universities shall be in accordance with the request of the rule of law spirit and the need of law school, 
to comprehensive strengthen the rule of law system culture construction, establish a perfect system. The system of rule of law in colleges and universities covers all aspects, such as running schools, managing schools, managing the Party, training personnel, scientific research and social services, there are two main aspects: One is external, including central and local higher education laws, regulations, policies etc, which itself contains the value elements of the core values, fully reflects the requirement of socialist morality, such as the Constitution, the Party Constitution, the law of higher education, etc, expression is very clear, only need to carefully sort out, classified compilation, keep pace with the times, add and delete in time. The other is inside, colleges and universities develop the legal system according to their actual need, both for the staff, and for young students, we should put the core value elements of core values to fully implement these specific rules and regulations, strengthen the school system enforceability and operability, ensure every school system, every key link has a distinctive value oriented. On the other hand, the law alone is not enough. Only through various forms to enable teachers and students to know, obey and respect by upholding these external, internal laws and regulations, and to accurately grasp the core value orientation and the ethical requirements embodied in it, strictly implement mandatory norms and the rigid constraints long-term, timely praise the virtues and good deeds, punish all kinds of violations of law online and offline, the citation is to be commended, the exhortation is to be exhortative, the punishment for punished, and to ensure that any fault would be punished, fault and punishment is match, with the authority and the deterrent of the rule of law to escort the cultivation and practice of the core values, so that staff and students could gradually form good habits, consciously external rigid constraints as an inner moral character, more firmly practicing the core values.

\section{Acknowledgements}

This work was financially supported by Special Project of University Philosophy and Social Science Fund of Jiangsu Province Education Department(Research on the cultivation and practice of socialist core values by means of network platform in Higher Vocational Colleges, 2017SJBFDY683), The Key Project of Scientific Research Institute of Taizhou Polytechnic College (Study on the value cultivation and practice path research of socialist core values in Colleges and Universities under the Internet plus vision, TZYKY-17-4), and Research Project of Party Construction of Taizhou Polytechnic College (Research on the path of systematic cultivation and practice of socialist core values in Colleges and Universities, DJ2015006).

\section{References}

[1] Beijing, May, 3. Nurture men of talent, minors in moral and law to grasp the rule of law talents Study hard to promote the growth of youth inspirational progress[N], People's Daily, 2017-5-04(1).

[2] Xi Jinping. Youth should be consciously practice the socialist core values[N], Guang Ming Daily, 2014-5-05(2). 